\section{LA-UR- $9 \%-2586$}

Approved for public release. distribution is unlimited.

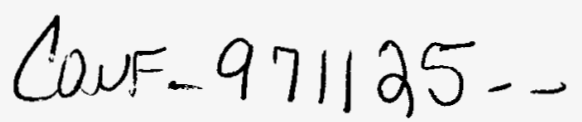

Title:

Target/Blanket Design for the Accelerator Production of Tritium Plant

Author(s):

M.W. Cappiello

A692? 97

Q. 3 . 1

Los Alamos National Laboratory, an affirmative action/equal opportunity employer, is operated by the University of California for the U.S. Department of Energy under contract W-7405-ENG-36. By, acceptance of this article, the publisher recognizes that the U.S. Government retains a nonexclusive, royalty-free license to publish or reproduce the published form of this contribution, or to allow others to do so, for U.S. Government purposes. Los Alamos National Laboratory requests that the publisher identify this article

as work performed under the auspices of the U.S. Department of Energy. The Los Alamos National Laboratory strongly supports academic freedom and a researcher's right to publish; as an institution, however, the Laboratory does not endorse the viewpoint of a publication or guarantee its technical correctness. 


\section{DISCLAIMER}

This report was prepared as an account of work sponsored by an agency of the United States Government. Neither the United States Government nor any agency thereof, nor any of their employees, make any warranty, express or implied, or assumes any legal liability or responsibility for the accuracy, completeness, or usefulness of any information, apparatus, product, or process disclosed, or represents that its use would not infringe privately owned rights. Reference herein to any specific commercial product, process, or service by trade name, trademark, manufacturer, or otherwise does not necessarily constitute or imply its endorsement, recommendation, or favoring by the United States Government or any agency thereof. The views and opinions of authors expressed herein do not necessarily state or refiect those of the United States Government or any agency thereof. 


\title{
TARGET/BLANKET DESIGN FOR THE ACCELERATOR PRODUCTION OF TRITIUM PLANT
}

\author{
M.W. Cappiello \\ Los Alamos National Laboratory MS H816 \\ Los Alamos, NM 87455 \\ (505) 665-6408
}

\begin{abstract}
The Accelerator Production of Tritium Target/Blanket (T/B) system is comprised of the T/B assembly and the attendant heat removal systems. The T/B assembly produces tritium using a high energy proton beam, and a spallation neutron source. The supporting heat removal systems safely remove the heat deposited by the proton beam during both normal and off-normal conditions. All systems reside within the T/B building, which is located at the end of a linear accelerator. Protons are accelerated to an energy of $1700 \mathrm{MeV}$ at a current of $100 \mathrm{~mA}$ and are directed onto the $\mathrm{T} / \mathrm{B}$ assembly. The protons interact with tungsten and lead nuclei to produce neutrons through the process of nuclear spallation. Neutron capture in ${ }^{3} \mathrm{He}$ gas produces tritium which is removed on a continual basis in an adjacent Tritium Separation Facility (TSF). The T/B assembly is modular to allow for replacement of spent components and minimization of waste. Systems and components are designed with safety as a primary consideration to minimize risk to the workers and the public.
\end{abstract}

\section{INTRODUCTION}

The Accelerator Production of Tritium (APT) project is part of a Department of Energy (DOE) dual track strategy to supply tritium to support the long term needs of the nation's nuclear weapon stockpile. Tritium decays at a rate of $5.5 \%$ per year, and must be replaced on a regular basis. The conceptual design of the APT plant is complete and the location has been chosen for construction at the Savannah River Site. The current schedule is for construction to start in 1999, and for operation to begin in 2007. DOE has established a National Project Office headquartered at Los Alamos to lead the APT effort. Burns and Roe Enterprises, Inc., in cooperation with General Atomics, has been selected as the prime contractor. The Westinghouse Savannah River
Company has been chosen as the operator. Together these partners will complete the development and demonstration activities; engineering and design; construction of the plant; and commissioning.

\section{TARGET/BLANKET BUILDING}

The APT T/B system is housed in a building located at the end of the $1.3 \mathrm{~km}$ long linear accelerator. Figure 1 shows an isometric of the building, including some of the major structures. The proton beam enters the building through the high energy beam transport (HEBT) system at $1700 \mathrm{MeV}$ and $100 \mathrm{~mA}$ of current. The resulting power in the beam is $170 \mathrm{MW}$. The beam passes through a series of magnets which expands it into a rectangular shape approximately $0.16 \mathrm{~m}$ wide by $1.60 \mathrm{~m}$ tall. The HEBT operates at a vacuum level of $1 \times 10^{-5}$ torr, and includes beam diagnostic systems to continuously monitor the beam and ensure its proper expansion and location.

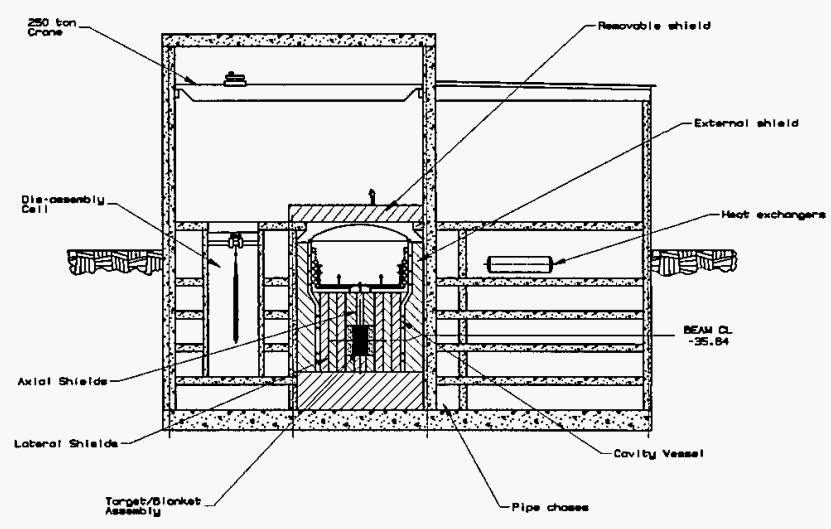

Figure 1. Target/Blanket building.

The expanded beam is directed onto the T/B assembly, which is located within a concrete cavity approximately 20 
x 20 meters square. Inside the cavity is a large vessel that houses the T/B modules and operates at a rough vacuum of 1 torr. The pressure boundary between the vessel and the HEBT is the proton beam window, which the expanding beam passes through. Located outside the vessel is sufficient steel and concrete shielding to allow personnel access to adjacent rooms during operation.

All support equipment required for operation of the T/B system is located in the building. This includes the storage pool for spent targets, a waste preparation hot cell, gas handling equipment, coolant cleanup systems, and other ancillary equipment. The product gas from the T/B assembly is purified within glove boxes in the T/B building, and transported to an adjacent TSF in small diameter tubes. The TSF uses existing technology that has been demonstrated at full scale to separate the tritium from the ${ }^{3} \mathrm{He}$ carrier gas. Pure ${ }^{3} \mathrm{He}$ is returned to the T/B building on a continual basis.

Figure 2 shows an isometric view of the T/B assembly with some of the major components identified. The overall length of the T/B assembly is $7.8 \mathrm{~m}$ and the width is $3.4 \mathrm{~m}$. The assembly is housed within a stainless steel vessel $10 \mathrm{~m}$ in diameter. Iron shielding between the assembly and the vessel wall keeps radiation damage to a minimum. All of the T/B and shield components are in the form of modules that are designed to be removed and replaced remotely. This strategy allows for replacement of short-lived components, maintenance and repair, and provides flexibility to update or adapt the design for different production goals if the need arises.

APT is planned to operate at an overall plant availability of 71 to $75 \%$. The maintenance schedule includes weekly, monthly, and annual outages. Unplanned outages are factored into an integrated reliability analysis to ensure the overall availability goal can be met. During the scheduled annual outage, spent components from the T/B will be replaced. All operations are done remotely. The retargeting is done in canyon type area that contains the $\mathrm{T} / \mathrm{B}$, storage pool, and disassembly hot cell. The overhead crane is used to lift modules from the T/B to either the storage pool or the disassembly cell. The canyon wall provides sufficient shielding so that this operation can be done safely.

\section{SAFETY}

Safety has a direct impact on the design decisions and has been an important consideration throughout the conceptual design. The safety by design approach has been adopted as an overriding philosophy. This approach embodies four main goals:
- Systems, components, and materials are chosen to minimize hazards and waste.

- Passive design features are incorporated where possible so that even unmitigated off-normal events result in negligible releases.

- Systems and components are designed with defense in depth (multiple barriers and redundancy).

- Components and structures are built to higher standards where costs are reasonable.

Incorporating this approach not only results in protection of the workers and public, but provides for increased reliability, production assurance, and low environmental impact. Some of the design features that have been incorporated as a result of this approach include natural circulation capability in the heat removal system; a safety class beam trip system that makes use of redundant and diverse methods for reliable beam shut down; redundant active residual heat removal systems; and a cavity flood capability.

In addition to the engineered systems, the T/B assembly has some inherent features which enhance the safety and environmental aspects of making tritium. Because neutrons are produced by spallation of tungsten and lead rather than fission of uranium and plutonium, no actinide or fission product waste is produced and criticality accidents are impossible. Also, the decay heat from the spallation process is typically less than $1 \%$ of the full power level, which simplifies the design of residual heat removal equipment that mitigates postulated accidents.

\section{TARGET/BLANKET ASSEMBLY}

The major components of the T/B assembly are shown in Figure 2. These include the proton beam window, the tungsten neutron source, the neutron decoupler, the lateral blanket, the reflector, the upstream blanket, the downstream blanket, the shield inside the vessel, upper vessel internals, gas-handling systems, and the cavity vessel. Each is described in detail below.

\section{- Proton Beam Window}

The proton beam window is a double-wall Inconel structure that separates the high-vacuum environment of the beam expander from the rough-vacuum environment of the T/B cavity vessel. The nominal $100 \mathrm{~mA}$, $1700 \mathrm{MeV}$ proton beam exiting the accelerator passes through the window, losing only a slight amount $(\sim 4$ $\mathrm{MeV}$, or $0.2 \%$ ) of energy. At the window position the beam spot size is $0.134 \mathrm{~m}$ wide by $1.44 \mathrm{~m}$ high. At the tungsten neutron source $2 \mathrm{~m}$ downstream of the window, the beam spot has expanded to $0.16 \mathrm{~m}$ wide by $1.60 \mathrm{~m}$ high. The heat deposited in the window struc- 


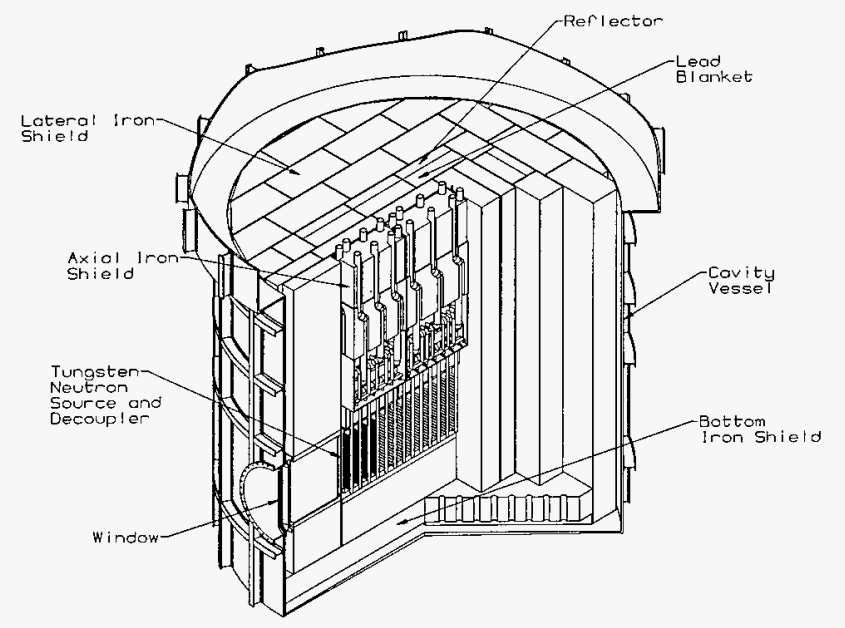

Figure 2. Target/Blanket assembly.

ture is about $600 \mathrm{~kW}$ and is removed by a low-pressure light-water coolant. Because of the low decay heat, a separate active residual heat removal is not required.

\section{- Tungsten Neutron Source}

After passing through the beam entrance window, the proton beam expands to $0.16 \mathrm{~m}$ wide by $1.60 \mathrm{~m}$ high and strikes a centrally located tungsten neutron source that is heavy-water cooled. Approximately $64 \mathrm{MW}$ of heat is deposited in the tungsten. The function of the tungsten neutron source is to efficiently use the highenergy proton beam to produce a primary source of neutrons and other high-energy particles. The neutron source is shown in Figure 3. It consists of small Inconel-clad tungsten rods assembled in horizontal stainless-steel tubes. These horizontal tubes are manifolded into larger diameter vertical inlet and outlet pipes, which provide a coolant flow of heavy water at moderate pressure (xx MPa) with an inlet temperature of $50^{\circ} \mathrm{C}$. The horizontal and vertical tubes make up a structure called a ladder. The tungsten neutron source consists of 13 such ladders separated into two modules, one containing six ladders and the other seven. Because of similar lifetimes and mechanical simplification reasons, the tungsten neutron source is combined with the decoupler and first blanket row (described below) to form the two integral modules.

The tungsten neutron source design is the result of extensive optimization and trade-off studies of the interacting blanket geometry, physics, thermal-hydraulics, safety, and mechanical designs. Because the power density decreases by a factor of 11 from the front ladder to the back ladder, the amount of tungsten per ladder is increased to maintain similar total power

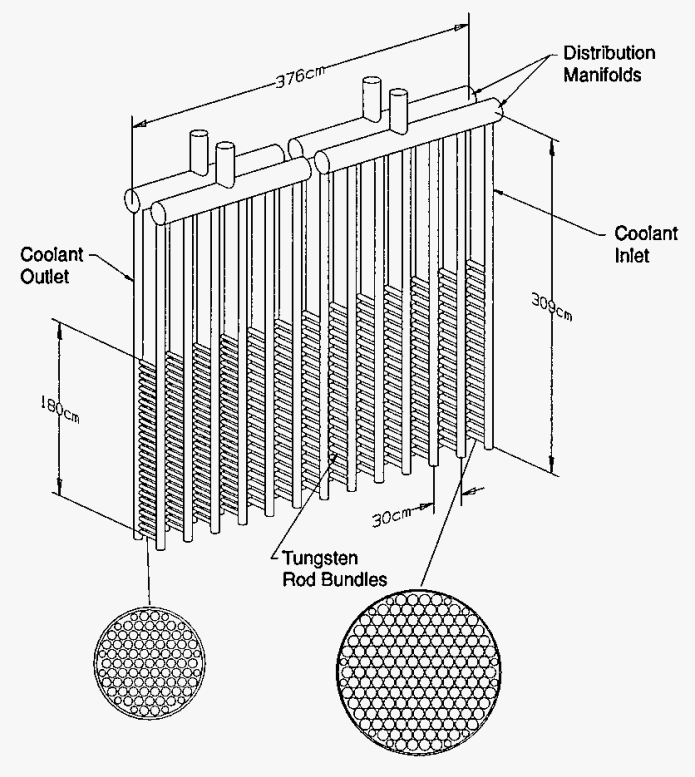

Figure 3. Neutron source assembly.

per ladder, and to flatten the neutron source distribution. To accomplish this, the rod diameters increase from $0.3175 \mathrm{~cm}$ in the front ladder to $0.5556 \mathrm{~cm}$ in the back. In a similar manner, the rung tubes vary from $4.04 \mathrm{~cm}$ to $7.43 \mathrm{~cm}$.

The peak power density in the neutron source peaks in ladder two at a level of $2.45 \mathrm{MW} / \mathrm{l}$. In this ladder, the tungsten rods are $0.3175 \mathrm{~cm}$ in diameter to provide adequate heat transfer surface area. Bundle exit temperatures are $85{ }^{\circ} \mathrm{C}$, coolant velocities are $5.13 \mathrm{~m} / \mathrm{s}$, and the minimum departure from nucleate boiling ratio is 2.26 , assuming a $23 \%$ power peaking factor above the nominal. The maximum clad surface temperature of $164{ }^{\circ} \mathrm{C}$ occurs in ladder 7 , and the maximum rod center temperature of $198{ }^{\circ} \mathrm{C}$ occurs in ladder 2 . The maximum duct wall temperature is $135^{\circ} \mathrm{C}$ in ladders 1 and 2 . All these temperatures are well below any temperature limits imposed by material considerations. Both unheated and heated flow tests are being performed to confirm all of the critical thermal hydraulic parameters.

\section{- Decoupler}

High-energy particles scattered out of the tungsten neutron source leak into the surrounding blanket modules after passing through a decoupler region that surrounds the tungsten neutron source. The decoupler region consists of several rows of tightly packed aluminum tubes containing ${ }^{3} \mathrm{He}$ with light-water coolant flowing outside 
the tubes under moderate pressure. The ${ }^{3} \mathrm{He}$ in this region preferentially absorbs the low-energy neutrons that scatter from the lead blanket toward the tungsten neutron source, thus maximizing neutron absorption in ${ }^{3} \mathrm{He}$ and minimizing neutron absorption in tungsten. The helium pressure is maintained at $0.9 \mathrm{MPa}$ (130 psia) to ensure optimum tritium production. Because there is only light elements in the decoupler (aluminum and water), energy deposition is low and the peak operating temperature reaches only $62{ }^{\circ} \mathrm{C}$ in the tubing.

- Lateral Blanket

A blanket region surrounds the tungsten neutron source and decoupler. The total power that is deposited in the blanket is $60 \mathrm{MW}$. It is approximately $120 \mathrm{~cm}$ thick and $350 \mathrm{~cm}$ high in the lateral direction, and about 50 $\mathrm{cm}$ thick above and below the target. The blanket region contains lead, ${ }^{3} \mathrm{He}$ gas, aluminum, and lightwater coolant in various fractions that are optimized in each region to meet thermal-hydraulic safety margins while maximizing the tritium production. The lead in this region provides an additional source of neutrons from additional spallation and $(n, x n)$ reactions. Neutrons are moderated to low energy by collisions in the lead and light water, and are captured in the ${ }^{3} \mathrm{He}$ gas to produce tritium. As shown in Figure 4, the blanket lead is enclosed in cruciform-shaped aluminum rods. The ${ }^{3} \mathrm{He}$ gas is contained in blind circular aluminum tubes (closed at one end) that are manifolded together at the top and sealed off at the bottom. The rods and tubes are assembled into aluminum housings which form the pressure boundary for the light-water coolant. Tritium produced in the ${ }^{3} \mathrm{He}$ diffuses and advects upward to the manifold, where it is removed by a flow of ${ }^{3} \mathrm{He}$ gas. The ${ }^{3} \mathrm{He}$ and tritium mixture is continuously transported to the tritium separation facility located in close proximity to the T/B building.

The blanket region is subdivided into rows that are based on the local power density in the lead. The rows immediately surrounding the tungsten neutron source receive the highest particle fluxes, and therefore experience the highest power densities. Moving outward from the tungsten neutron source, the lead power density drops steeply. To accommodate this variation, the amount of lead, ${ }^{3} \mathrm{He}$, and coolant is tailored to the power density to maximize tritium production. This is done by changing the thickness of the lead rods, the diameter of the ${ }^{3} \mathrm{He}$ tubes, and the flow channel gaps. There are three row types for the high (up to 100 $\mathrm{W} / \mathrm{cm}^{3}$ ), medium (up to $20 \mathrm{~W} / \mathrm{cm}^{3}$ ), and low (less than $5 \mathrm{~W} / \mathrm{cm}^{3}$ ) power density regions, respectively. The row 1 blanket regions have the highest volumetric heating

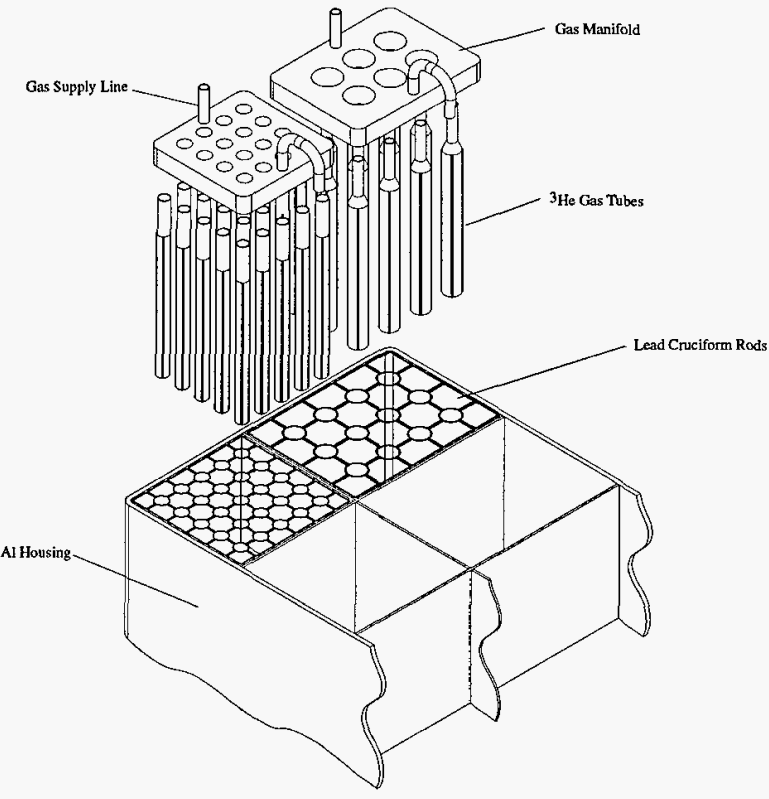

Figure 4. Typical blanket assembly.

rates in the lead, and as a consequence have the smallest volume fractions of lead and the largest coolant volume fractions. The row 2 and rows 3-5 blankets have lower heating rates and correspondingly higher lead volume fractions and lower coolant fractions. To accommodate the range of power densities, the rod flat to flat dimensions are increased from $\mathrm{xx} \mathrm{cm}$ in row 1 to $\mathrm{xx} \mathrm{cm}$ in row 3-5. Peak aluminum structure temperatures are less than $115^{\circ} \mathrm{C}$. The coolant pressure is nominally $0.48 \mathrm{MPa}$ or lower.

As in the case of the tungsten neutron source, the various blanket rows adjacent to the row-1 blanket are combined into modules. Blanket rows 2 and 3 are mechanically and hydraulically coupled because of similar lifetime and power levels. Blanket rows 4, 5, and the reflector are also coupled for similar reasons. Behind the tungsten neutron source is the downstream blanket region that is split into three separate modules similar to the lateral blanket. Towards the front of the assembly is the upstream module. The total number of modules is 19, which includes the proton beam window.

- Reflector

The blanket is surrounded by a reflector region that contains light water and ${ }^{3} \mathrm{He}$ gas. The reflector reduces the overall neutron leakage from the blanket and enhances tritium production. This region consists of an aluminum housing through which light water is circu- 
lated to serve as coolant and reflector material, and blind aluminum tubes that contain ${ }^{3} \mathrm{He}$.

\section{- Upstream and Downstream Blanket}

Between the window and the tungsten neutron source is the upstream blanket region. The primary function of the upstream blanket is to provide a channel through which the proton beam passes while capturing neutrons from the target. Additionally, it shields the upstream portion of the cavity vessel, reducing its activation. This 2-m-long region is composed of a decoupler, a lead blanket, and reflector, all light water cooled. Located directly behind the tungsten neutron source is the downstream blanket region. It consists of a decoupler region followed by approximately $150 \mathrm{~cm}$ of blanket, and is similar in design and construction to the lateral decoupler and blanket designs.

\section{- $\quad$ Shield}

Iron shielding surrounds the blanket and reflector to minimize activation of the vessel and external structures and to protect workers. In addition, iron shields above the $\mathrm{T} / \mathrm{B}$ region minimize activation of the upper vessel structures. The first 100 to $200 \mathrm{~cm}$ of shielding that surrounds the blanket and reflector requires active cooling. This is done with light-water cooling panels that are mechanically attached to the shield blocks. Outside this region, the power density is sufficiently low that active water cooling is not required.

\section{- Upper Vessel Internal Structures}

The upper vessel houses a number of structures that provide all of the utilities required to operate the $T / B$ modules. This includes headers for heavy-water and light-water coolant, connecting piping from the headers to the modules, ${ }^{3} \mathrm{He}$ gas line connections, and instrumentation lines. All piping that feeds and returns coolant to the modules and all gas connections are designed for remote connect and disconnect.

\section{- Gas Handling systems}

The gas handling systems consist of the ${ }^{3} \mathrm{He}$ gas transport, cavity atmosphere, and low pressure ${ }^{3} \mathrm{He}$ recovery. The ${ }^{3} \mathrm{He}$ gas transport system delivers the ${ }^{3} \mathrm{He}$ and tritium mixture to the tritium separation facility. All gas lines are welded and use double-walled tubing between the modules and the tritium separation glove boxes. Gas from the modules contains a mixture of ${ }^{3} \mathrm{He}$ with tritium, other hydrogen isotopes, and impurities. After extraction of the hydrogen isotopes and the removal of impurities, pure ${ }^{3} \mathrm{He}$ is returned to the T/B system modules.

The cavity atmosphere system consists of a pumping system to evacuate the air from the vessel down to a pressure of 1 torr along with gas sensors and controls. The evacuated gasses will be continuously monitored for indications of water ingress, ${ }^{3} \mathrm{He}$, hydrogen, or tritium gas. Controls will direct the gas flows through a gas clean up system, a ${ }^{3} \mathrm{He}$ recovery system, and to an exhaust system. This system is designed to accommodate a modest ingress of water and air into the vessel from the valves, fittings, and penetrations.

The low pressure ${ }^{3} \mathrm{He}$ recovery system collects the gas from numerous areas in the T/B facility and transports the gas back to the TSF. The recovery system collects gases from the cavity vessel, the coolant loops, the vacuum line jackets, and glove boxes in the T/B facility. These gases are processed to separate the ${ }^{3} \mathrm{He}$ and hydrogen isotopes from the contaminants, to maintain a clean gas stream to the TSF.

\section{- Cavity Vessel system}

Encasing the T/B assembly and some of its shielding, is a sealed stainless-steel pressure vessel. The vessel is cylindrical in shape with a removable head structure for access and extraction of internal components. It provides a vacuum atmosphere for the beam to pass through, minimizing air activation. It is also the confinement boundary and radionuclide barrier in the event of an internal coolant leak or a ${ }^{3} \mathrm{He}$ gas line leak. To provide a backup heat removal mechanism during postulated accidents, the cavity can be flooded with water from the adjacent storage pool. During a cavity flood condition, the vessel serves as the pressure boundary for the flood coolant.

\section{HEAT REMOVAL SYSTEM}

There are four separate heat removal systems that service the modules: one heavy-water system that cools the tungsten, a light-water system that cools the high and medium power blanket regions, a light-water system that cools the low power blanket/reflector and shield, and a light-water system that cools the window.

Each heat removal system includes a primary loop, an intermediate loop, and a tertiary loop which provides the heat sink. To provide high availability and ease of operation, the heat removal systems are operated at low temperature and pressure. No attempt is made to recover the heat for electricity production. Within the individual loops, in- 
line spare pumps are also provided to further increase availability.

During operation, the coolant streams directly in the proton beam become activated due to spallation of the oxygen in the water, and from spallation product recoil from cladding materials. Purification systems continually remove spallation products and maintain the appropriate chemistry to manage corrosion. Intermediate loops transfer heat from these primary systems to a cooling tower loop and provide a barrier for the release of radionuclides. Because the coolants are low pressure and temperature, no flashing will occur in the case of a leak or break.

\section{MATERIALS}

Due to radiation damage, the window and neutron source modules are expected to require replacement every one to three years. The expected lifetime of the blanket modules is three to 10 years, and the outer blanket lead and reflector/shield modules should last the plant lifetime of 40 years. A replaceable beam entrance window, and modular proton beam inserts used for materials science and isotope production, have been demonstrated successfully at the Los Alamos Neutron Science Center (LANSCE).

The highest radiation damage rates occur in the front ladders of the tungsten neutron source. Here the proton fluence averages $5 \times 1021 \mathrm{p} / \mathrm{cm} 2$ and the neutron fluence $2.9 \times$ $1022 \mathrm{n} / \mathrm{cm} 2$ per year of operation. This corresponds to a calculated displacement per atom (dpa) value of about 10 . Data obtained from fission reactors, and accelerators to date support the fact that adequate ductility will remain in the baseline APT materials at this level of exposure. A comprehensive in-beam test program is underway to provide the detailed information that is necessary for the final design. In addition, a material surveillance program will be implemented at the APT plant to monitor material behavior in the components during their expected lifetime.

Because of the high-temperature strength and oxidation resistance of Inconel-718, it is the material of choice for both the tungsten rod cladding and the proton beam window. Use of Inconel 718 minimizes corrosion during operation and maintains integrity during postulated accidents. Extensive experience exists with Inconel as a proton beam window at LANSCE. Its beamstop window is a double-wall structure with water-cooling, made of Inconel-718. When removed after six years of intermittent service, the LANSCE window had not failed and it had accumulated an average proton fluence of $1.3 \times 1022 \mathrm{p} / \mathrm{cm} 2$. It was replaced as a matter of routine maintenance.

For the blanket structure, 6061 alloy aluminum is the chosen reference material, for cladding the lead cruciforms and for containing the ${ }^{3} \mathrm{He} /$ tritium gas in the high-neutron flux regions. Stainless steel can also be used to contain the gas, but with a loss in neutron production due to the parasitic absorptions in steel. In this region, proton fluences and therefore the radiation damage is significantly lower. The peak occurs in the downstream blanket decoupler at a value of $1.32 \times 1020 \mathrm{p} / \mathrm{cm} 2$ per year, which is a factor of 44 lower than the tungsten neutron source.

For the shielding, carbon steel and stainless steel are both suitable candidates. However, to accommodate potential corrosion due to the presence of very low levels of moisture, the use of stainless steel or corrosion-inhibiting coating would be attached to carbon steel. At LANSCE, carbon steel shield blocks are coated with aluminum to control corrosion.

The cavity wall is a very large structure that must hold the rough vacuum, support the internal structures, and be a highly reliable radionuclide retention boundary. For this application, stainless steels are the materials of choice. There is a considerable experience base for stainless steel structures and at the temperature expected, the strength of these materials is adequate.

\section{PHYSICS}

Neutrons in the T/B assembly are produced by nuclear spallation of the tungsten and lead. Spallation refers to nuclear reactions that occur when energetic particles (in this case high energy protons) interact with an atomic nucleus (the "target" nucleus). The initial collision between the incident particle and the target nucleus leads to a series of direct reactions, termed "intranuclear cascade," where individual nucleons or small groups of nucleons are ejected from the nucleus. After the intranuclear cascade phase of the reaction, the nucleus is left in an excited state. It subsequently relaxes to its ground state by "evaporating" nucleons, mostly neutrons. At $1700 \mathrm{MeV}$, approximately 40 neutrons are produced in the T/B per incident proton.

The LAHET (model-based) Monte Carlo code (Ref. 1) and the MCNP (data-based) Monte Carlo code (Ref. 2) are the primary tools used for physics analysis. CINDER' 90 (Ref.3) is used to calculate time-dependent radionuclide build-up, decay heat, and depletion. Calculations using these codes have been carried out to determine the tritium production, detailed energy deposition, decay heat, material activation, material damage, and shielding requirements. Analyses have been performed to determine optimum materials, volume fractions, coolant types, beam spot size and aspect ratio, blanket dimensions, reflector dimensions, material fractions, ${ }^{3} \mathrm{He}$ content and location, and many other 
design options.

The calculated tritium production by region is shown in Figure 5. Nearly $36 \%$ of the tritium is produced in the decoupler region, where thermal and fast neutron fluxes are high. Most of the remainder (56\%) is produced in rows 1 through 3. Rows 4 and 5 and the reflector regions produce $8 \%$ of the total.

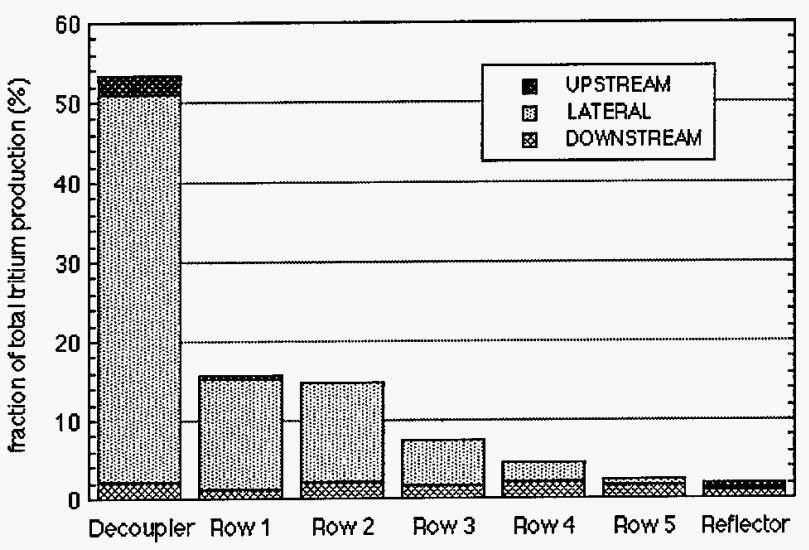

Figure 5. Tritium production by region.

The spallation process is endothermic, and therefore very efficient from a heat deposition standpoint per neutron produced. For every neutron released from tungsten and lead, about $8 \mathrm{MeV}$ of energy (which is the binding energy per nucleon in these nuclei) is converted to mass. Therefore, of the $170 \mathrm{MW}$ of beam power incident on the T/B, only $130 \mathrm{MW}$ is converted to heat, which must be carried away. Approximately $38 \mathrm{MW}$ is converted to mass, while the remainder leaks from the system in the form of neutrinos. There are no delayed neutrons as in fission reactions. About half of the total power under normal operating conditions is deposited in the tungsten neutron source. The other half is deposited in the regions surrounding the tungsten neutron source.

Immediately after beam turnoff, decay heat generated by the radioactive products is generally on the order of $1 \%$ of the steady-state power. Most regions have decay powers less than $0.1 \%$ of their respective steady-state powers after ten days cooldown. For input to safety calculations, the decay power of each ladder assembly is determined, as this is the source of most of the radionuclides in the T/B. At time zero after beam shutdown, the total power of all 13 ladders is $483 \mathrm{~kW}$. This drops to $142 \mathrm{~kW}$ after one day, 49 $\mathrm{kW}$ after five days, and $35 \mathrm{~kW}$ after 10 days. Retargeting will require approximately 5 days of cooldown before transfer of the tungsten neutron source module to the storage pool. At this time, excessive heating of the tungsten would not occur even if forced cooling was lost.

\section{CONCLUSION}

The APT T/B is a robust design based on existing technology. Where possible, proven materials and component designs are used. To accommodate uncertainties in predicted lifetimes, the design is modularized to allow for a straightforward replacement of spent components. The thermal hydraulic design is well within allowable limits and because of the low temperature and pressure systems, offers additional safety and reliability benefits. The safety by design process has incorporated passive design features, redundancy, and defense in depth to provide adequate protection of both the worker and the public.

\section{ACKNOWLEDGMENTS}

The author is indebted to the following individuals who contributed to the information and data provided in this paper: Gary Russell, Eric Pitcher, Russell Kidman, William Wilson, Walt Sommer, Stuart Maloy, Laurie Waters, Ron Parker, Leo Sanchez, Ron Barber, Brian Smith, Gordon Willcutt, James Anderson, Jack Edwards, Rick Pelfrey, John Edwards, Michael Todosow, and George Greene.

\section{REFERENCES}

[1] Prael and H. Lichtenstein, "User Guide to LCS: The LAHET Code System," Los Alamos National Laboratory report LA-UR 89-3014 (September 1989).

[2] MCNP

[3] Cinder90 
M97988972

Report Number (14) $\leq A-4 R-97-2586$ CONE-971125=-

Publ. Date (11)
Sponsor Code (18) $\frac{199708}{\text { DOELDP } \times F}$
UC Category (19)
UC-70O DOELER 